\title{
ORGANIZATIONAL DIVISIONS IN BIM-ENABLED COMMERCIAL CONSTRUCTION
}

\author{
Carrie S. Dossick, P.E., M. ASCE ${ }^{1}$ and Gina Neff $^{2}$
}

Forthcoming in Journal of Construction Engineering \& Management

\begin{abstract}
Proponents claim that the adoption of Building Information Modeling (or BIM) will lead to greater efficiencies through increased collaboration. In this paper, we present research that examines the use of BIM technologies for mechanical, electrical, plumbing, and fire life safety systems (often referred to as MEP) coordination and how the introduction of BIM influences collaboration and communication. Using data from over 12 months of ethnographic observations of the MEP coordination process for two commercial construction projects and interviews with 65 industry leaders across the U.S., we find that BIM-enabled projects are often tightly coupled technologically, but divided organizationally. This means that while BIM makes visible the connections among project members, it is not fostering closer collaboration across different companies. We outline the competing obligations to scope, project and company as one cause for this division. Obligations to an individual scope of work or to a particular company can conflict with project goals. Individual leadership_especially that of the MEP coordinator in the teams we studied—often substitutes for stronger project cohesion and organization. Organizational forces and structures must be accounted for in order for BIM to be implemented successfully.
\end{abstract}

\footnotetext{
1 Assistant Professor, Department of Construction Management, Box 351610, University of Washington, Seattle, WA 98195 USA; cdossick@u.washington.edu.

2 Assistant Professor, Department of Communication, Box 353740 University of Washington, Seattle, WA 98195 USA; gneff@u.washington.edu.
} 
SUBJECT HEADINGS: Information systems; Information technology; Communication; Integrated systems; Constructability; Construction industry; Mechanical systems; Electrical systems; Leadership

\section{INTRODUCTION}

As building projects become more complex, project participants diversify into areas of special expertise. Diversification in turn requires communication, collaboration and coordination between specialized trades. The balance between diversification and integration on projects has long been a problem for management scholars (Lawrence and Lorsch 1967), and even more so in the temporary, cross-organizational teams common in design and construction. Today the mechanical, electrical, plumbing, and fire life safety (MEP) systems of a building can be as much as $40 \%$ of the scope of a commercial construction project. With increasing building complexity, the development, design and construction of MEP systems requires increasing collaboration not only among the MEP specialties, but also with the architect, contractor, mechanical and structural engineers.

Building Information Modeling (BIM) makes explicit the highly interdependent nature of structure, architectural layout, and the MEP systems by technologically coupling project participants together. By this we mean that the work of individual MEP detailers are imported into an integrated computer system known as a three-dimensional consolidated model, thus making more explicitly the physical intersection of individual MEP scopes of work. But even as their awareness of others' work increases, MEP detailers' ability to collaborate across companies does not. The MEP detailers we observed worked for MEP subcontractors and were organizationally separated from the architects and engineers on their project. These architects 
and engineers, however, had information and decision-making power that the subcontractors felt was vital to their jobs.

Within this organizational infrastructure, we have identified three often competing obligations of people working in contemporary commercial construction: Scope, Project and Company. In this paper, we begin to explore how these competing obligations undermine the goals of project collaboration and the ways in which project leadership from the general contractor is relied upon (successfully or not) as a mechanism for overcoming these conflicts. We selected the MEP coordination process because in many ways it is a synecdoche, or a part that is representative of the whole, of the collaboration challenges facing the design and construction industries as they adopt Building Information Modeling.

Our findings on MEP detailers suggest that the process of substituting leadership for project cohesion may occur elsewhere in the design and construction process. Although there are efforts in the industry to create collocated or otherwise more closely connected collaboration teams, as a general rule, the architectural and engineering design teams are fairly isolated from the construction teams, including MEP coordination teams like those we studied. These design teams may not be aware of the impact their work has on others on the project. It is also rare to have direct and open lines of communication between architectural and engineering design teams and subcontracting construction teams. Of this indirect communication, one structural engineer told us in an interview, "Sometimes you just want to be able to talk to the people who know what you're talking about.” Even as technological advances such as BIM enable the potential for closer collaboration and better information exchange, decision-making power in building projects is often divided organizationally. 
The three-dimensional geometry of BIM, in theory, allows project participants to more easily communicate spatial and logistical issues, as well as improve access to information on material and performance specifications and requirements. What we have found in practice, however, was that while BIM linked project participants more tightly together technologically, they remained organizationally divided, often lacking timely access to crucial information and decisions. Based on the ethnographic research that we have done, we find that the industry is relying heavily on the individual leadership of particular people in the MEP coordination process to substitute for closer communication connections among trades and among construction divisions - a strategy that works only when strong, effective leadership is in place.

This paper proceeds as follows: First, we review related work on what causes successful technology adoption both in the AEC industry and in general. Then we describe our research method and research setting. Next we outline our findings on how BIM enables organizational loose coupling and technological tight coupling in the MEP coordination process and suggest a theory of competing obligations of scope, project and company. Finally, we conclude that the introduction of BIM alone is not sufficient for increased collaboration and suggest future directions for practitioners and scholars.

\section{RELATED WORK: WHAT CAUSES SUCCESSFUL TECHNOLOGY ADOPTION}

Buildings "have a complex social and material manifestation whose organized production is reliant on shared frames of reference” (Beamish and Biggart 2006), such as standards of practice, legal arrangements, and industry norms (Whyte et al. 2008). New technologies have the power to disrupt these shared frames of reference by making explicit power struggles among distinct occupational groups (Barley 1986; Bechky 2003). Scholars are still divided on how the introduction of new technology can effectively support collaboration because people use new 
technology tools to reassert professional status and difference, to restructure organizational forms, and to revisit previous distinctions and divisions among people in teams and organizations (Barley 1986; Bechky 2003; Orlikowski 2000).

These power struggles and organizational shifts occur as individuals, teams and companies navigate through changes to legal risks associated with standards of practice, concerns over intellectual property, financial risks associated with capital investments in hardware and software, and the investment needed to train and maintain technologically-skilled staff (Allen et al. 2005). In the AEC industry, competitive advantage, process problems, technological opportunity, and institutional requirements drive the adoption of innovative tools such as Building Information Modeling (Mitropoulos and Tatum 2000). Some argue that that new technologies (and BIM in particular) are an opportunity to change work practices (American Institute of Architects 2006; CURT 2005), while the research of others suggests that successful adoption depends on allowing teams to adapt the technologies to suite their existing work practices (Hartmann 2008).

Successful technology depends on many factors including people's attitudes towards the technology, corporate culture, relationships between companies, characteristics of the specific projects, industry wide issues of legal precedents, communication density, organizational barriers, and individual's resistance to change (Nithamyong and Skibniewski 2006; O'Brien 2000). Personal attitudes towards new technology adoption are shaped by the risks involved in using unproven means and methods; by the difficulty in implementing technology in particular settings; by financial risks involved; and by the perception of other workers' attitudes towards new technologies (Paulson and Fondahl 1980; Tatum 1989). Even when companies commit the 
resources needed for technological change, project participants do not necessarily participate equally (Cuff 1991).

This can lead to an approach within the AEC industry which focuses on individual attitudes and characteristics as the driving force behind technology adoption with the study of personal styles and approaches to change (Maher et al. 1998; Moore 2002). But technology adoption cannot be divorced from its organizational setting. BIM models can function as a coordinating artifact to encourage conversations about the organization chart, work process and work flow, and clarification of work, leading to greater satisfaction with meetings (Liston et al. 2007). When teams establish realistic expectations and a team spirit, technology adoption is more successful (Hartmann 2008). When such teams bridge the intersection of design and construction companies they produce more novel solutions to project problems from which both parties benefit (Taylor 2007).

Building Information Models could provide solutions for organizational and technological challenges facing the AEC industry, and research to date shows that with good organizational design, BIM can result in positive team dynamics for joint problem solving. New technologies may have the power to change organizational structure but scholars still do not fully understand what organizational forces need to first be in place for effective collaboration to occur after new technologies are introduced. Our study is an attempt to rectify the current focus on individual attitudes towards technology adoption, to situate leadership into an organizational context, and to begin to identify the organizational challenges to successful BIM-enabled collaboration. 


\section{SETTING AND METHODOLOGY}

For studies of technology in the workplace, there is a long tradition of using ethnographic methods and "grounded theory” (Glaser and Strauss 1967) to ascertain how people use tools in practice, the ways in which tool adoption changes power within the workplace, and how new organizational structures emerge when new tools are introduced (Barley 1986; Bechky 2003; Huang et al. 2006; Orlikowski 2000).

We observed two commercial building projects and interviewed participants on each project. The research team took detailed field notes on how technology was used, the interactions among meeting participants, and discussions about project logistics. In addition to spontaneous, informal interviews that occurred before and after meetings, meeting participants were formally interviewed individually for 15 to 40 minutes. We use pseudonyms for all project participants in this paper. We also collected and analyzed all information that circulated among meeting participants such as logs of clashes, emails about the coordination schedule, and digital snapshots of the digital model showing clashes between different building systems. While we did not formally analyze Requests for Information (RFIs), several of the meeting notes and interviews directly address project RFIs.

Hill and Valley are pseudonyms for two urban, commercial, negotiated design-bid-build construction projects in the same city, built by the same general contractor. Hill is a 450,000 sq. ft. (41,806 sq. m.) mid-rise complex commercial office building. Valley is a 300-unit high-rise mixed-use residential building with retail and parking. For each project, we observed the series of MEP coordination meetings among the detailers from subcontractors for sheet metal ductwork, piping, plumbing, fire protection, and electrical systems and project staff from the general contractor. Eight to ten people participated in these weekly meetings, which were lead by 
the general contractor's MEP coordinator. For both projects, the MEP coordination and clash detection process was part of preparation of the fabrication and installation documents and lasted 12 to 18 months. A research team of one faculty researcher and one graduate student were primarily responsible for attending each meeting (12 months of observations of the Hill project and seven months for the Valley project) and writing detailed field notes as soon as possible after the meeting.

Both projects utilized Building Information Models to coordinate work among various subcontractors. During weekly meetings, detailers from the subcontractors involved in MEP coordination would meet to examine the combined individual efforts of their digital detailing-a digital model that consolidated their individual 3D drawings. From this consolidated model, conflicts between the systems, or clashes were automatically and manually observed for reconciliation during the meeting. The consolidated model functioned to highlight potential conflicts and to help the project participants solve them before field installation began. The model coordinator working solo or in a pair managed the projection of the consolidated model during the meeting, navigated through the model, and either led the meeting through the discussion of conflicts in the model, project timelines, and other issues.

As part of this study, we also interviewed 65 architects, engineers, and builders from across the U.S. who were not affiliated with the case studies and asked them about their experience using BIM, their strategies for communicating across AEC industries, and the challenges that they face in collaborating on large-scale commercial projects.

We analyzed field notes and interview data using an emergent, iterative coding schema in Atlas.ti, a qualitative analysis program, to identify recurring themes which we discuss below. 


\section{ORGANIZATIONAL LOOSE COUPLING \& TECHNOLOGICAL TIGHT COUPLING}

Although it is technologically possible to link models together for closer collaboration among all players in a large commercial construction project, the teams we studied were organizationally separate in terms of information, decision-making power, and involvement. This organizational separation, or organizational loose coupling, was one of the main challenges that the teams we studied faced when using BIM. Building Information Modeling created a tight technological coupling among the teams who shared models, but caused frustration by making visible the loose organizational coupling on the project. By this we mean that the effectiveness of the consolidated model broke down when organizational barriers prohibited the communication of information and decisions about the consolidated model.

The organizational structures of a commercial building project typically separate design and construction teams (see Figure 1). In environments where team members are collocated and informal communication is encouraged, information request-response latency can be reduced to a matter of minutes, as compared to days in more traditional design organizations (Chachere et al. 2004). However, in teams like the ones we studied information and communication flows could occasionally take months through the formal written channels. In Figure 1, the dashed arrows represent lines of communication that were not directly open for our teams.

In the two projects we observed, MEP detailers communicated formally with the architect and mechanical and structural engineers through Requests for Information (or RFIs) and sleeving drawings that identified where MEP systems penetrate concrete slabs, shear walls and beams. As shown in Figure 1, both types of documents were routed through the general contractor and the architect before finally reaching the engineer who could make a decision or provide a clarification. The response flowed in reverse, causing frustrating delays on both sides. 


\section{INSERT FIGURE 1 ABOUT HERE}

In the Hill project, one detailer lamented that the MEP team could not get the information they need to do their work. When asked what could have been done to resolve this challenge the detailer replied, "I think, if anything there should be, like in these meetings—-[the architect] should be here, a representative for them, so we could get quick responses, and they understand what our problems are. There are probably some answers they can't answer right then and there, but we’ve never ever had [the architect] there.” Instead of direct communication with design teams, detailers depended on the General Contractor's MEP coordinator to navigate through the project organization to communicate MEP issues to the other contractors and designers and to get information from them back to the MEP team. Even though this was a problem of organizational separation, the detailers blamed the MEP coordinator for a lack of leadership when communication through the project hierarchy broke down.

\section{BIM as a set models}

Each construction project did not have a single Building Information Model, but many different models, each with its own attachment to authority and organizational control. Figure 2 illustrates a consolidated model as a linked network of relatively independent models. These distinct digital models were linked into one picture, but remained under separate organizational jurisdictions until the "as-built" stage. 


\section{INSERT FIGURE 2 HERE}

Figure 2 shows a digital combination of distinct scope models-a structural steel model, a model of the HVAC system, an electrical conduit model, etc. As architects and engineers refined the building systems in each of the projects we studied, the subcontractor detailers revised their corresponding models. As they worked these details out, detailers referred to models and plans (known as backgrounds) by the architect, structural engineer and (in certain instances) the mechanical and electrical engineers for their own work. They also referenced other trades, such as concrete and fire proofing on steel members and slabs, in order to design around other systems already in place in the consolidated model. However, conflicts arose around passing information and models across organizational boundaries. The MEP coordination team was tightly coupled. Even though detailers came from several different organizations, their models frequently required changes to adapt to the work of other team members. Detailers met frequently and shared information with one another. Between meetings they would call each other to discuss specific issues and resolve conflicts between their systems. Within the project as a whole, however, organizational divisions between the detailers and the other project participants separate decision makers from those who are executing designs.

\section{Organizational Separation: The Problem of the Structural Steel Drawings}

Even though our teams met weekly, it was difficult for people in both projects to establish trust in the information that the model presented from outside the MEP group, trust in the competency of others in the MEP group as to their use of the model, and trust in the technology itself 
(Dossick et al. 2008). There remained much frustration over the lack of particular types of information, especially from people who were outside of the MEP coordination process.

For example, detailers on the Hill project were concerned from the beginning about the accuracy of the structural steel drawings. Although the general contractor had modeled the structural steel using an older set of two-dimensional drawings, the detailers were worried because, as one said, “We don’t know how good it is.” Because of the tight coordination necessary for many of the floors, knowing the steel location and fire proofing dimensions with some precision made a significant difference for MEP coordination: a few inches difference could jeopardize months of work. As such, subcontractors had a large degree of uncertainty about the precision of the model. When asked about the challenges of the project, one detailer said

lack of information, like ... regular structural drawings ... is an important factor in what we do. We route things around the structure and that was an ongoing problem, getting the structural drawings, the shop drawings, and just maybe not having all the information to do the job ... I guess you just kind of got to go with the information you have and just kind of wing it and hope for the best and try to make-like if there looks like there might be a beam in the way or something, you maybe make a few phone calls to like an engineer or something and say "Hey, can you tell me what the dimensions are so I can bring my busway through and not hit your beam.” That kind of thing.

This same uncertainty occurred on the Valley project as well, where detailers noted that the architectural model and the structural model did not "match up.” They repeatedly asked for verification of wall locations, but this issue went unresolved for months. 
Our interviews show that while 3D modeling is common among structural engineers, it is still extremely rare for structural engineers to share these models with other project participants. The Hill project was no exception. In October, Frank, one of the detailers for the mechanical subcontractor complained in the meeting “we’ve been waiting for steel drawings for two months.” At this point, Frank complained that the lack of drawings “is holding us up.” Since they were modeling around the general contractor's interpretation of the structural drawings, the detailers wanted confirmation that the digital model they were using was current, correct and reliable. Other detailers added "We need confirmation" and "If we can get the real approved drawings that would be the best.”

In November, the issue continued to be discussed. Sam, the general contractor's MEP project engineer expressed the difficulty of coordinating across the organizational divisions when said of the structural engineering firm, "I am trying to get them to play ball, which is the hard thing to do. They're being difficult and haven’t posted up more drawings.” Sam explained that the reason he was given was that the steel drawings were not finished, an explanation that everyone found difficult to accept given the fact that fabricated steel was arriving on site.

The general contractor’s BIM coordinator had already tried to open one digital model from the steel detailer but it was digitally corrupted. When the shop drawings finally came to the MEP detailers after months of requests for the digital model, they were in 2D Acrobat PDF format, dated six months prior, and stamped “not for construction purposes”-none of which inspired trust or confidence in the information quality on the part of the detailers.

The general contractor's MEP project engineer, Sam, bore the brunt of the MEP detailers’ frustration at the lack of a 3D structural steel model. One detailer explained, 
I think you've got to get the person who is the MEP lead in this case, he has to be really—he has to know what he's doing. And I think that's part of the reason why we're having so many difficulties is [Sam] not knowing everything that has to be—and understanding, I guess, the [BIM computer] program itself.

Team members expected Sam to be able to navigate around organizational obstacles and experienced his failure to do so as a lack of leadership.

We would argue instead of individual skill or lack thereof, the real source of the problem on the Hill and Valley projects was the fact that although the MEP detailers were closely connected solving problems together in a technology-enabled coordination process, they were organizationally disconnected from basic information that they felt they need to do their jobs. Detailers on both the Hill and Valley projects felt frustrated and trapped within their communication and organizational system. Their work depended on the decisions made by the architects, engineers, general contractors and other trades, but they themselves often had very little influence over those decisions. Even though they were jointly doing complex MEP coordination that relied on a great deal of precision within the consolidated model, they felt their work could be jeopardized by the lack of precise information from the engineers (Hill) and architects (Valley). The detailers felt that they did not have the information necessary for their work, much less that they were empowered to influence decisions made by the architect, structural engineer, steel shop drawing detailer, fabricator or erector.

This counters much of the current rhetoric about the possibilities of BIM as a way to encourage closer collaboration among design and construction professionals. We found that although BIM technology tied MEP coordination team participants together through the coconstruction of consolidated models, there were organizational divisions that kept them from 
collaborating outside of this group. MEP detailers in both cases did not trust the digital information that they had, did not feel empowered to get the information for themselves, and felt forced to rely upon formal communication channels in which they were isolated from people who had the information they needed. These two projects relied on the individual leadership of people like the MEP project engineer to traverse the organizational landscape to get information for their teams and trades. In the next section, we suggest a theory of conflicting obligations to describe the organizational forces that push people away from as well as towards good collaboration.

\section{CONFLICTING OBLIGATIONS: SCOPE, PROJECT, \& COMPANY}

Generalizing from our cases and interviews, we argue that individuals in a construction project face conflicting obligations to scopes, projects, and companies. These obligations, as we will see below, can be at odds with the goals of the project itself and BIM-supported collaboration. In these two particular cases, the MEP detailers had obligations to their scopes of work, creating details for systems to meet building codes and regulations and advocating for their particular system within the project as a whole. At the same time, they also had obligations to their own companies, whose ownership and management placed expectations on them and provided the context in which they worked. Since detailers were often scheduled on more than one project at a time and faced the challenge of balancing their work among multiple projects simultaneously. People working to create successful cross-organizational collaborative teams on construction projects must address competing scope and company obligations in order to create projectoriented teams.

Table 1 outlines how we saw these conflicting obligations in the MEP coordination process. Each detailer came to the project with a specific mandate—a legal and ethical 
requirement for his or her scope of work within the building systems. They were temporarily organized around one specific project with the goals of effective collaboration, while working for independent companies with profit requirements.

\section{INSERT TABLE 1 ABOUT HERE}

Table 1 outlines the relationships of these obligations to the larger project—-the tasks, actions, and values associated with the obligation—and a typical approach to collaboration that accompanies the obligation. Clearly, some individuals by their very nature are more teamoriented and more likely to collaborate than others who retreat into their own scopes of work (Maher et al. 1998). Our typology, though, attempts to map out the organizational positions that influence and constrain successful collaboration so that particular individuals could be more or less able and inclined towards collaboration based on the strength of their other obligations. For a project to be optimally successful and efficient, the conflicting obligations to scope and company need to be resolved.

\section{Obligation to Scope}

In both Hill and Valley projects, each detailer had a specific scope of work, but their work often relied upon the decisions and designs of others. The level of collaboration in weekly MEP meetings ranged from a strict exchange of information, to negotiation among different detailers over space and conflicts, to group problem-solving in which detailers jointly brainstormed options and optimized solutions. The personal attachment to scope was evident in these meetings when detailers identified their scopes of work with personal pronouns, mixing the terms for self with the terms for scope. For example, one of the Hill project detailers looking at the consolidated model said of a conflict, “That's not me, that's a steel beam.” 
In general, separation from the project organization as a whole compounds the focus on individual scopes of work. For example, in the Hill and Valley projects when detailers lacked communication from architects or structural engineers, they expressed less commitment to the building project than to getting their own scopes completed. Organizational separation among architects, engineers, the general contractor and the subcontractors created a culture among the MEP team in which commitment to individual scopes of work often overshadowed their expressed commitment to the project as a whole. The organizational separation of construction professionals from design professionals in our cases created communication challenges that reinforced the obligations to individual scope, at the expense of commitment to the building project.

One detailer from the Valley project referred to project-level collaboration as "all stuff that I don't really have time to get involved in—-the why's and where's and why is the schedule the way it is, and who is dictating all this," saying that he "just have to live with it and fight for my right for more time.” The work flow was such that the detailers worked within constraints dictated to them from the design documents and had limited access to the designers to discuss these constraints. Consequently, it was exceptionally difficult for the detailers to propose even small changes to the overall design of the project in order to make their work fit within the space allotted, much less propose more effective, efficient solutions for which they have expertise, as is often the case with complex, high-efficiency building systems. It is in this way that detailers had very little influence over the building project as a whole, and they felt constrained by project decisions in which they had no voice. While they may have a lot of experience and ideas about how to resolve conflicts or small design changes that would allow them to best install their systems, within the Hill and Valley project organizational structures detailers had very little 
leverage or ability to present these ideas and solutions let alone explain what their own work is, why it is important, and what it takes to accomplish it. As one detailer from the Valley project explained,

They never give enough time for plumbing, never. It’s like the sprinkler guy can just take his sprinkler pipes and he doesn't have to worry about being inside walls or piping up to a toilet or a bathtub and all the fittings and offsets that are involved and all this. There's so much more involved in putting a plumbing system together than there is in anything else. And nobody seems to understand that they need to allow more time. I don't know, it’s just like nobody cares. That's my attitude, nobody really cares how it impacts us.

Certainly, the job to design and build a specific building system is only one piece of the larger project. However, their organizational separation from decision makers and the design and engineering process disenfranchised detailers and created stronger obligations to individual scopes and to their respective companies than to the building project as a whole. One detailer from the Valley project described a project that was not going well and said that he was frustrated with the MEP coordination process. Instead of feeling motivated by the project as a whole, his focus was on "his" field guys—or the people who would be installing the building system that he detailed, saying, "my priorities are always to support my field guys, and doing all this other hullabaloo is strictly to do the show."

\section{Obligation to Company}

Company obligations emphasize the financial, legal, and logistical requirements for an independent firm working on a building project. In subcontractor companies, obligations to company goals influence the decisions about the marketplace and allocation of personnel and 
time across different projects. Company obligations prioritize the values of optimizing profits with respect to time across multiple projects.

An example of how the company obligation can conflict with the project goals occurred on the Hill project. The management of the electrical subcontractor decided to pull their detailer off the project and instead hired an inexperienced field superintendent to complete the detailed design. This decision by the electrical subcontractor company disrupted the cohesion that had been achieved by the MEP coordination team and slowed down the work for other the detailers who were forced to work with someone new to both the team's process and to BIM. In this case, the obligation to company needs outweighed the obligation to project, with a detrimental impact on the project collaboration.

We also found examples of financial expectations that drove the willingness to collaborate on projects. A mechanical detailer in charge of plumbing on the Valley project explained the bind that he found himself in when needing to get information from the engineer:

As far as they're concerned, nobody has any money left on the job, so everybody has backed out of it, and we are the ones that are left to suffer through it, because it's always the budget, you know. The plumbing engineer is extremely kind, but he'll be more than happy to answer questions, but he says, you know, we don't have any money left on this job to work on it. So that's typical, too. There's never anybody that has any money to do things right after the job is already out.

In this quote, doing what is right for the project was juxtaposed with the contract, budget, and management for a particular engineering company. Working outside of the budget constraints to help answer questions is seen as being "kind" to others working on the project, not as the expectation for successful projects. The ability to balance the profit and other obligations of 
company with an obligation to the completion of the project is one of the places that we found the sharpest conflicts among the MEP team and the rest of the building design and construction teams.

The company obligation also encouraged case study participants and those we interviewed to avoid exposure to risk, which appears to be one of the key obstacles to sharing information in BIM-enabled construction projects. In interviews, structural and mechanical engineers reported that their companies were reluctant to share 3D models with builders because of issues of liability. Issues of ownership, intellectual property and design liability were all reported as obstacles to sharing BIM models and working collaboratively in BIM. In the Hill project for example, printouts of the structural steel drawings stamped "Not for Construction Purposes” signaled that the obligation to protect the engineering company from liability outweighed the need for MEP project participants to have current, precise information.

\section{Conflicts with the Obligations to the Project}

A construction project brings together a temporary team from across several companies for one specific purpose. In the MEP process we studied, the general contractor's MEP project engineers focused in particular on creating lines of communication, solving problems, and managing information flow among these players. This work entailed negotiations among trades, owner interests, and architectural and engineering design requirements. The actors on both projects we studied experienced unanticipated intersections between their scopes and between scope and project, and this is where many of the most contentious and difficult conflicts occurred. These surprises were at times costly, and strong, effective leadership from the MEP project engineer or other project participants was need to help the group navigate these conflicts, get information from people outside the MEP coordination team, and advocate for design changes that would 
benefit the project as a whole. In the absence of personal leadership from the MEP coordinator to get actors with overarching company obligations to, in Sam's words, "play ball” with the project's needs, detailers felt frustrated.

In the Valley project, an example of a conflict between obligations to scope and to project arose between Margo, mechanical detailer responsible for the HVAC systems and Larry, an electrical detailer. During a meeting to discuss the coordination of a mechanical room, Larry addressed Margo with a concern about the placement an air handler unit above a transformer. Margo insisted that a condensate protection pan under the air handler would be sufficient protection against condensation dripping on the electrical systems. Larry then addressed the group at large about the need for access to the transformer and the air handler and mentioned that the building inspector will be quite strict about access to the control panel and filters. Reiterating his concern, Larry suggested that Margo move her systems for the benefit of the project. Later in the meeting, the general contractor announced that the architect and engineers will attend a MEP coordination meeting the following week, to which Larry asked "Will the right people be there? We need to make a good decision," ostensibly referring to the mechanical engineer and the unresolved conflict he and Margo had between their systems in the mechanical room. Larry, trying to solve the problem among the MEP team members rather than the lengthy RFI process, then asked Margo for the submittal document that shows the details of the air handler that Margo specified. Margo responded defensively, saying that her "submittal" and an RFI regarding the issue had not been approved, adding "I am not doing anything until they tell me to," referring to the mechanical engineer and the general contractor who had the power to resolve the issue. When Larry continued to discuss the issue, Margo stridently told Larry, “I don’t take direction from you.” 
This exchange exemplifies how conflicting obligations across scope, company, and project impede effective collaboration. While Larry was looking to gather the information and solve problems collectively, Margo defended her scope, her personal knowledge of building codes, and her ability to navigate the organizational structure by sending a formal question to the engineer (who had yet to answer her). Margo's reliance on direction from the general contractor and the design team also shows the organizational constraints of project, in which collaborative problem solving among experienced MEP detailers still is less valued by many participants than, in Margo’s words, waiting to let others “tell you what to do.” Larry and Margo could have worked through this problem together, and the General Contractor’s MEP project engineer pushed for a joint solution within the coordination process instead of the slower option of communicating through organizational chain and waiting for a response. Even within their own scopes of work, however, Larry and Margo were disenfranchised from project-level decisions. This disenfranchisement, in turn, created conflicts and frustration within the team, limited collaboration and reinforced the obligation to individual scopes and companies instead of their joint project.

\section{LEADERSHIP AS A SUBSTITUTE FOR ORGANIZATIONAL STRUCTURE}

Building Information Modeling encourages a process of collaborative virtual building before physical construction begins and pushes project participants to work through their scopes collaboratively in three dimensions. However, as we found in our two ethnographic case studies, the exchange of accurate information and group collaboration were hindered by the conflicts of both scope and company obligations with the requirements for genuinely collaborative projects.

In interviews, when people with BIM experience reported extreme satisfaction with projects, strong leadership was credited as one of the keys for success, and in our two cases, 
project participants targeted the leadership of the MEP project engineer as the source of their frustration with the project. One detailer from the Hill project, referred to the importance of the general contractor’s MEP project engineer when he said, "If you have a good guy, you win.” Another Hill detailer described the MEP project engineer as “a little bit green and needs a little education as far as what it takes to do a MEP coordination,” adding “that’s been kind of a hindrance, his lack of some experience.” A Valley detailer noted that on his project the "the leadership was just wishy-washy... You can’t just throw somebody in to do this big coordination and put somebody in who has no idea how to even work the system.” In contrast, on another project he had worked on, "they knew what they were doing, versus this team which has no idea what they are doing. It's different if you're working with a team that's got it together... [when] people who were running the show were much more knowledgeable and understood the construction industry better.”

Although the data from our comparative projects does not directly address the elements of good leadership in construction projects, in both cases project participants considered these projects as examples of ineffective leadership. Our findings suggest that in general leaders in the MEP coordination process are saddled with the daunting tasks of navigating through a labyrinthine organizational structure for answers to crucial questions; of negotiating among conflicting obligations of scope, company, and project interests; and of pushing for collaboration and joint problem solving among sometimes recalcitrant project participants. These findings suggest that general contractors rely heavily on the individual leadership of MEP project engineers and other key individuals as a substitute for organizational structures that would encourage closer collaboration among project participants. The industry seems to be relying on good leaders who can bring the team together and provide information and confidence to come 
out of their own scopes of work to complete the work collaboratively, rather than face the challenges of restructuring projects organizationally to support collaborative work.

\section{CONCLUSION: THE NEED FOR BETTER STRUCTURED TEAMS}

Although BIM technologies have been presented as a solution to collaboration challenges in the industry, we find that projects with BIM face organizational challenges that limit collaboration. Whether a project is BIM-enabled or not, organizational and cultural divisions between designers and builders and between contractors and subcontractors may stifle collaborative work and joint problem-solving, even as the expertise needed for buildings becomes increasing complex and professionally differentiated. To overcome the organizational disincentives inherent in scope and company obligations, construction projects rely on individual leadership to hold the people together and inspire collaboration. Our interview data confirms that good leaders can inspire project participants to increase their focus beyond their individual scope towards the common goals of the project. Without an inspirational leader who can navigate a complex yet disperse project hierarchy, acquire much needed information, and strongly represent the interests of his or her team at the project level, collaboration will be limited to exchanges of information rather than joint problem-solving and optimization. In such a case team members will focus on their obligations to individual scopes and companies rather than the project as a whole.

In our interviews, successful collaboration leaders reported that they leveraged the forces of scope and company obligations to bring the teams together. They advocated for group problem-solving collaboration that benefits the individual companies. In this way, they did not put the project as odds with the demands of scope and company, but philosophically aligned the goals of collaboration with these demands. 
We hypothesize that our analysis of the particular case of MEP coordination may be applicable more broadly across the disciplinary divisions and segregated organizational structure of commercial construction. Be they personnel from the owner, architect, engineer, general constructor, or subcontractor organization, each project participant is brought into the project with a specific scope orientation, and has a tentative temporary alliance to the project while having a more permanent obligation to their company.

Suggestions of revised contracting practices to incentivize collaboration could solve some of these issues, but our research suggests that conflicts between scope and project will still remain. Throughout the network of project organizational structure, effective project-oriented leaders at all levels navigate the communication infrastructure to exchange information, encourage joint-problem solving, and inspire collaboration in spite of conflicting obligations of scope and company. Implementing BIM alone is not sufficient for solving these problems. Further research could investigate what aspects of cross-company collaboration are more likely to produce better buildings more effectively. For project leaders, our research suggests that managing team members’ expectations about the limited impact of BIM on project hierarchies of could reduce some of the frustrations caused by organizational loose coupling.

\section{ACKNOWLEDGEMENTS}

This research was supported by the University of Washington’s Royalty Research Foundation, the Dean's Development Award in the College of Built Environments, and the Department of Communication. Research assistance from Naila Crawford, Kristin Gustafson, Christopher Harihar, and Helen Juan is gratefully acknowledged. We send a very heartfelt thank you to the case study participants. We want to thank the organizers and attendees of the 2008 LEAD 
conference whose inspired dialog enriched this analysis, and we wish to thank three anonymous reviewers for their helpful comments.

\section{REFERENCES}

Allen, R. K., Becerik, B., Pollalis, S. N., and Schwegler, B. R. (2005). "Promise and Barriers to Technology Enabled and Open Project Team Collaboration.” Journal of Professional Issues in Engineering Education \& Practice, 131(4), 301-311.

American Institute of Architects, C. o. I. P. (2006). “Report on Integrated Practice.” American Institute of Architects, Washington, D.C.

Barley, S. R. (1986). “Technology as an Occasion for Structuring: Evidence from Observations of CT Scanners and the Social Order of Radiology Departments.” Administrative Science Quarterly, 31(1), 78-108.

Beamish, T. D., and Biggart, N. W. (2006). "Markets as Regimes: Explaining Change and Stability, Competition and Consensus in Economic Orders.” University of California, Davis, Davis, Calif.

Bechky, B. A. (2003). “Object Lessons: Workplace Artifacts as Representations of Occupational Jurisdiction.” American Journal of Sociology, 109(3), 720-752.

Chachere, J., Kunz, J., and Levitt, R. (2004). “Can You Accelerate Your Project Using Extreme Collaboration? A Model Based Analysis.” 2004 International Symposium on Collaborative Technologies and Systems, Stanford University.

Cuff, D. (1991). Architecture: The Story of Practice, MIT Press, Cambridge, MA.

CURT. (2005). “Optimizing the Construction Process: An Implementation Strategy.” Construction Users Roundtable. 
Dossick, C. S., Neff, G., and Juan, H. (2008). “Analyzing the Ramifications of Building Information Technologies for Collaboration in Architecture, Engineering, and Construction.” 12th International Conference on Computing in Civil and Building Engineering \& 2008 International Conference on Information Technology in Construction, Beijing, China.

Glaser, B. G., and Strauss, A. L. (1967). The Discovery of Grounded Theory: Strategies for Qualitative Research, Aldine de Gruytner, Hawthorne, NY.

Hartmann, T. (2008). “A Grassroots Model of Decision Support System Implications by Construction Project Teams “ Ph.D. Dissertation, Stanford University, Palo Alto, CA.

Huang, E. M., Mynatt, E. D., and Trimble, J. P. (2006). “Displays in the Wild: Understanding the Dynamics and Evolution of a Display Ecology.” Fourth International Conference on Pervasive Computing, Springer-Verlag, Dublin, Ireland.

Lawrence, P. R., and Lorsch, J. W. (1967). "Differentiation and Integration in Complex Organizations.” Administrative Science Quarterly, 12(1), 1-47.

Liston, K., Fischer, M., Kunz, J., and Dong, N. (2007). “Observations of Two MEP iRoom Coordination Meetings: An Investigation of Artifact Use in AEC Project Meetings.” CIFE Working Paper, Stanford University Stanford, Calif., 59.

Maher, M. L., Cicognan, A., and Simoff, S. J. (1998). “An experimental study of computer mediated collaborative design.” International Journal of Design Computing, 1, 10-20.

Mitropoulos, P., and Tatum, C. B. (2000). "Forces driving adoption of new information technologies.” J. Constr. And Mgmt., 126(5), 340 - 348.

Moore, G. A. (2002). Crossing the Chasm: Marketing and Selling High-Tech Products to Mainstream Customers, Harper Business Essentials, New York. 
Nithamyong, P., and Skibniewski, M. J. (2006). "Success/Failure Factors and Performance Measures of Web-Based Construction Project Management Systems: Professionals' Viewpoint.” Journal of Construction Engineering and Management, 132(1), 80-87.

O’Brien, W. J. (2000). “Implementation Issues in Project Web Sites: A Practitioner's Viewpoint.” Journal of Management in Engineering, 16(3), 34-39.

Orlikowski, W. J. (2000). “Using Technology and Constituting Structures: A Practice Lens for Studying Technology in Organizations.” Organization Science, 11(4), 404-428.

Paulson, B. C., and Fondahl, J. W. (1980). “Toward Improved Transportation Construction Through Research.” The Construction Institute, Stanford University, Stanford, Calif.

Tatum, C. B. (1989). "Organizing to increase innovation in the construction firm.” Journal of Construction Engineering and Management, 115(4), 602 - 617.

Taylor, J. (2007). “Antecedents of Successful Three-Dimensional Computer-Aided Design Implementation in Design and Construction Networks." Journal of Construction Engineering and Management, 133(12).

Whyte, J., Ewenstein, B., Hales, M., and Tidd, J. (2008). "Visualizing knowledge in ProjectBased Work.” Long Range Planning, 41, 74-92. 
